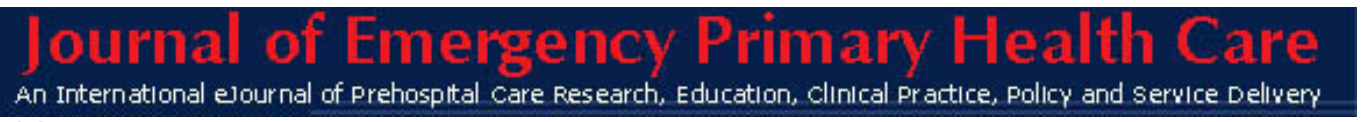

ISSN 1447-4999

\title{
EDITORIAL
}

\section{World Health Organisation (WHO) Conference on the Health Aspects of the Tsunami Disaster in Asia}

Article 990162

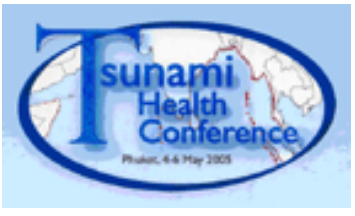

\section{Frank Archer}

The Asian Tsunami on $26^{\text {th }}$ December, 2004 has been referred to as "Black Sunday". The devastation and human consequences were graphically portrayed by the media in real time, to a stunned worldwide audience. The global response in terms of both tangible immediate response and ongoing humanitarian aid were swift, generous and substantial. The Melbourne "Age” recently "Counted the Cost”:

> "More than US\$11.4 Billion has been raised to rebuild Indian Ocean countries after the December 26 earthquake and tsunami, which killed 231,452 people. It is more than enough to meet the estimated needs.

$>$ Total damage: US\$10.73 billion

$>$ Rebuilding costs: US\$10.375 billion

$>$ People displaced: 1.77 million

$>$ Number of houses needed: 308,000

$>$ Number built or under construction: 46,000

$>$ Number of Boats destroyed: 103,829

$>$ Number of schools destroyed: more than 2,300

$>$ Ratio of women and children killed to men: 3:1"

The impact on the countries in the region affected by this widespread disaster varied, as did their preparation and responses to this catastrophic event. This disaster was unusual in its geographical scope and in the number of nations affected, and provided a range of challenges to meeting the health responses to this event. However, within six months, the WHO, in co-operation with the Ministry of Public Health of the Royal Thai Government, and in partnership with all affected countries in the region, convened the "WHO Conference on the Health Aspects of the Tsunami Disaster in Asia”. This conference, convened at a senior policy and expert practitioner level, "focussed on the lessons learnt in the health sector response to the Tsunami crisis response in the early phase of recovery, in the broader framework of efforts undertaken by the affected countries supported by international assistance”. The three-day conference was held in Phuket, Thailand and attended by approximately 300 delegates.

The specific objectives of the Conference were to: 
$>$ "Review health sector experience with response and early recovery so as to determine successes and limitations, i.e. what was done well, and what could have been done better? and;

$>$ Identify lessons learned for improving future health sector crisis response and recovery systems and processes, i.e. in what way can such future operations be better organised, and their technical components rendered more effective?”

The Conference addressed these objectives from the perspectives of (a) national actions taken in response and recovery, and, (b) actions taken by the international assistance community - especially United Nations, donors, Non-Government Organisations, and, specifically, the WHO.

The program was thoughtfully structured to meet the Conference objectives. Day 1 addressed the national health perspectives on the Tsunami crisis, with a speaker from each of the affected countries. Key issues including "Health Protection and Disease Prevention", "Health Services Delivery", "Health Policy and Co-ordination" and "Military-Civilian Co-operation", were each examined through a critical review of experience. The second day featured 18 workshops which addressed the wide-ranging health issues relating to the responses to the Tsunami. Each workshop was chaired by a well-briefed chairman, supported by a rapporteur and featured three speakers and a lead discussant as a prelude to open discussion. Each of the rapporteurs, at the conclusion of the day, met with "synthesising rapporteurs" who collated the 18 workshops in four themes for presentation of Day 3. On the final day, the synthesising rapporteurs presented "What Have We Learnt" and other keynote speakers addressed "How Can We Do Better". The closing session outlined the "Where To From Here". Further details of the structure and program for this outstanding Conference are available on the Conference website.

This Conference was a working conference in every respect and maximised the presence and contributions of all participants. The rapporteurs and synthesising rapporteurs played a major role in focussing the outcomes of the discussions. The most onerous task fell to Dr David Nabarro, the representative of the WHO DirectorGeneral for Health Action in Crises, who presented the Initial Conference Summary.

The full Conference proceedings will be published in Prehospital and Disaster Medicine in December 2005. These proceedings will be mandatory reading for anyone with an interest in the health response to disasters.

The WHO considered the outcomes of this Conference at its General Assembly later in May 2005, which were considered in the context of its strategy plan "Health Action in Crises - A Three-Year Program to Improve the Performance of the World Health Organisation". This plan is an acknowledgement that as significant as the Asian tsunami was, there are many other humanitarian emergencies ongoing at this present time, and, sadly, no doubt there will be more in the future.

As a participant in this Conference, I was left with the sense of three specific challenges for the global emergency response and humanitarian action community:

1. "Science and Health Action in Crises" - a number of speakers made observations that the global emergency response and humanitarian action community does not necessarily "learn the lessons" from previous major 
events. This leads one to wonder if a part of the reason is the lack of an international framework to build the "Science and Health Action in Crises". There are journals, academic centres, and multiple tools for needs assessment and evaluation, but my impression is that there is no structured approach or international body charged with collecting these multiple activities and collating them into a framework, which could represent the evolving science of "Health Action in Crises".

A review of the WHO "Health Action in Crises - a Three-Year Program to Improve the Performance of the WHO” identifies multiple research and knowledge goals, but does not explicitly consider specifically developing an over-arching framework to conceptually and systematically "build the science”.

On Day 3 of the Phuket Conference, the theme of co-ordinating assessments and evaluations was highlighted, but I was left with the impression that these were largely aimed towards co-ordination and response in the context of a particular event. However I would suggest that there is also the need to not only collate these multiple evaluations which could be used as case studies and which are valuable in their own right, but also to undertake independent research activities concurrent, and in parallel, with major events. The objective would be to add to a structured framework to evolve the "Science of Health Action in Crises". One possible framework which could be utilised as a global template is the "Health Disaster Management Guidelines for Evaluation and Research in the Utstein Style". The World Association for Disaster and Emergency Medicine (WADEM), and other appropriate bodies, should be encouraged and resourced to collaboratively build the "Science of Health Action in Crises”.

2. "Evidence-base for Disaster Health Interventions" - in his initial summary of the Conference, Dr David Nabarro identified the need to develop an "Evidence Base" for interventions in times of major events which threatened the health status of the community. A lead in this direction was taken by the Cochrane Collaboration commencing a few days after the Tsunami occurred. A working party lead by Mike Clarke (UK) see editorial and Sally Green (Australia), included a representative from each of the affected countries, and developed the Cochrane Collaboration's response under the heading "Evidence Aid". These initial activities identified systematic reviews relevant to the health response to the Tsunami which were available in the Cochrane Library. Health practitioners in the affected countries were generously provided with free access to the Cochrane Library by the publishers, John Wiley \& Sons Ltd, for 6 months post tsunami.

The working party is continuing its activities and, in consultation with representatives in the affected countries, has determined priorities for further systematic reviews to provide evidence to inform decision-making on appropriate interventions for future consideration. "Evidence Aid" was enthusiastically supported in a special workshop during the recent Cochrane Colloquium held in Melbourne in October 2005. The working party was encouraged to continue its activities and to broaden its scope to improve the evidence base for disaster health interventions for disasters in general and not specifically relating to the Asian Tsunami. Readers interested in contributing 
to the work of the Cochrane Collaboration in this endeavour are encouraged to contact the working party through Mike Clarke.

3. "Education and Training" - the general theme of the implications for education and training was highlighted by a number of rapporteurs from different perspectives. There was a general consensus of the need to "professionalise the humanitarian workforce", whilst at the same time recognising the current lack of international standards and guidelines for education and training in the multi-disciplinary response to major events which threaten the health status of the community. Again, the WHO threeyear program for health action in crises makes explicit a number of education goals. However, these goals, which tend to focus more on the delivery of education and training, appear to lack a consideration for an international framework to systematically develop effective, efficient and contemporary education programs with internationally endorsed quality assurance and global transferability.

Whilst two of the synthesising rapporteurs at this Conference, Prof. Ron Waldman, Columbia University, New York, and Prof. Debarati Guha-Sapir, Director, WHO Collaborating Centre for Research on Epidemiology of Disasters, Brussels, Belgium, encouraged professionalisation of the humanitarian workforce, Prof. Guha-Sapir also cautioned on the "(alarming) increase in short courses in this field”. Given the assertion of multiple myths in the general field of health action in crises, our failure to "learn the lessons" of the past, and, the high turnover of the humanitarian workforce, it may be timely to develop a "Research-Teaching Nexus" for this field in a structured international approach to develop international standards and guidelines for education and training. WADEM has taken the lead with an Issues Paper on this topic, however, further input is required from the global emergency response and humanitarian action community to bring this vision to reality.

WHO and the countries affected by the Asian tsunami, have been quick to critically review the health sector experience with response and early recovery to the Asian tsunami and have provided a searching examination of what was done well, and what could have been done better, and, have collated the lessons learnt to suggest structures and processes to improve future health sector crisis response and recovery. The challenge now is for the global emergency response and humanitarian action community to take these lessons on board and creatively engage with "Building Public Health Capacity for Disaster Management System for Health.” This we owe to the people affected by disasters and humanitarian emergencies in our global community. 